\title{
DESLOCAMENTO COMPULSÓRIO: RELATOS DE UM LUTO NÃO ELABORADO
}

Maria Lívia Pinheiro de Freitas

Universidade de Fortaleza - UNIFOR

Renata Bezerra de Holanda Bessa

Universidade de Fortaleza - UNIFOR

Karla Patrícia Martins Ferreira

Universidade de Fortaleza - UNIFOR

Hélida Arrais Costa Vieira

Universidade de Fortaleza - UNIFOR

Ada Raquel Teixeira Mourão

Universidade Federal do Piauí - UFPI
Recebido em: 17/08/2020

$1^{\text {a }}$ revisão em: 03/06/2021

Aceito em: 08/06/2021

\section{RESUMO}

As construções de barragens podem ocasionar à desapropriação de cidades inteiras e realocação de populações. Transformações desta amplitude geram perturbações às comunidades afetadas. Devido a construção da Barragem do Castanhão, a cidade de Jaguaribara foi destruída, e seus moradores transferidos para a primeira cidade projetada do Ceará, a Nova Jaguaribara. Apropriando-se dos conceitos da psicologia ambiental, a pesquisa teve como objetivo compreender aspectos da relação pessoa-ambiente frente ao deslocamento compulsório. Verificou-se na população de Jaguaribara sinais de luto não elaborado, traços de sofrimento psíquico, bem como a fragilização dos vínculos sociais e a redução da autonomia. Compreender as relações humano-ambientais, e impactos decorrentes de processos de deslocamentos programados torna-se primordial para a elaboração de estratégias que visem a redução de danos, potencializem adaptação e a promoção de saúde. Portanto, o impacto da perda do lugar torna-se viabilizador da manifestação e da manutenção de intenso sofrimento favorecendo o surgimento de adoecimentos.

Palavras-chave: luto; estresse; ajustamento social; psicologia ambiental; migração humana. 


\section{COMPULSORY DISPLACEMENT: REPORTS OF AN UNDEVELOPED MOURNING}

\section{ABSTRACT}

The construction of dams can lead to the expropriation of entire cities and the relocation of populations. Transformations with this magnitude has affected communities and caused too much disturbs. It has happened after the Castanhão Dam creation, the city called Jaguaribara, was destroyed and your citizens transferred to the first projected city in Ceará, Nova Jaguaribara. Appropriating the concepts of environmental psychology, the research aimed to understand aspects of the person-environment relationship in the face of compulsory displacement. The population of Jaguaribara showed signs of undeveloped mourning, traces of psychological distress, as well as weakened social bonds and reduced autonomy. Understanding human-environmental relations, and impacts resulting from programmed displacement processes, is essential for the elaboration of strategies that aim at harm reduction, potentiate adaptation and health promotion. Therefore, the impact of the loss of place makes the manifestation and maintenance of intense suffering feasible, favoring the appearance of illnesses.

Keywords: grief; stress; social adjustment; environmental psychology; human migration. 


\section{DESPLAZAMIENTO POBLACIONAL OBLIGATORIO: INFORMES DE UN LUTO NO RESUELTO}

\section{RESUMEN}

La construcción de presas puede conducir a la expropiación de ciudades enteras y la reubicación de las poblaciones. Transformaciones de esta magnitud generan disturbios en las comunidades afectadas. Debido a la construcción de la presa Castanho, la ciudad de Jaguaribara fue destruida y sus residentes fueron transferidos a la primera ciudad proyectada en Ceará, Nova Jaguaribara. Apropiando los conceptos de psicología ambiental, la investigación tuvo como objetivo comprender aspectos de la relación persona-ambiente frente al desplazamiento obligatorio. La población de Jaguaribara mostró signos de duelo subdesarrollado, rastros de angustia psicológica, así como lazos sociales debilitados y una autonomía reducida. Comprender las relaciones humanoambientales y los impactos resultantes de los procesos de desplazamiento programados es esencial para la elaboración de estrategias que tengan como objetivo la reducción de daños, potenciar la adaptación y la promoción de la salud. Por lo tanto, el impacto de la pérdida de lugar hace posible la manifestación y el mantenimiento del sufrimiento intenso, favoreciendo la aparición de enfermedades.

Palabras clave: luto; estrés psicológico; adaptación social; psicología ambiental; migración humana. 


\section{INTRODUÇÃO}

O Estado do Ceará sempre apresentou grande escassez de água devido à irregularidade do período chuvoso. Em decorrência dessa característica climática e com a intenção de minimizar o impacto causado pela irregularidade das chuvas e garantir o abastecimento hídrico nos períodos de seca no estado, o Governo Federal apresentou o projeto da construção da Barragem do Castanhão (Frota \& Duarte, 2016). Em sua delineação, a barragem seria construída no local onde se situava a cidade de Jaguaribara, inundando dois terços da cidade, incluindo a sede do município. Neste processo seria necessário o deslocamento programado em massa de toda a comunidade para uma nova cidade a ser construída: a "Nova Jaguaribara". Tal cidade é conhecida por ser, segundo dados do IBGE (2020), a primeira cidade cearense totalmente planejada, localizada a aproximadamente 50 $\mathrm{km}$ da antiga sede. Assim sendo, no ano de 1985, a vida dos moradores da pacata cidade atravessou uma intensa transformação com a chegada das primeiras notícias sobre a construção da barragem. $O$ nome Jaguaribara ainda permanece na nova cidade, mas, por questões didáticas e culturais, houve uma classificação: Antiga Jaguaribara (Pré-inundação) e Nova Jaguaribara (PósInundação), assim chamada por seus moradores.

De acordo com relatos dos moradores, na antiga Jaguaribara as casas tinham maior proximidade e eram no formato de casas conjugadas, o que propiciava relacionamentos bastante contíguos com fortes vínculos entre os habitantes. Havia alguns locais considerados importantes como a praça principal, que era tida como um lugar de prestígio, visto que era o local onde os moradores iam para conversar e se distrair. A economia girava em torno do plantio, colheita, pesca e o comércio de alguns produtos, incluindo a produção agrícola local. Lá também havia festas tradicionais, principalmente religiosas, como as comemorações voltadas à padroeira da cidade, festa de aniversário do município, dentre outras. Através dos relatos, identificou-se que os moradores tinham uma forte relação afetiva e enraizamento em relação à cidade (Frota \& Duarte, 2016; Leite, 2018).

O deslocamento programado da antiga cidade para a nova ocorreu sob enorme resistência dos moradores através do Movimento dos Atingidos por Barragens $(\mathrm{MAB})$, da Associação dos Moradores e da Igreja Católica. A resistência se manifestou, inicialmente, devido às incertezas em relação às condições socioeconômicas subsequentes à transição. Segundo Bertini (2015), a forte objeção ao processo de mudança se devia também ao fato de que a inundação da antiga cidade resultaria no aniquilamento histórico, social e cultural de toda aquela população. Contudo, apesar da relutância, em julho de 2001 as famílias começam a deixar suas antigas casas e, então, em 25 de setembro do mesmo ano, Nova Jaguaribara torna-se realidade e nova morada para os habitantes da antiga sede e para alguns moradores da área rural, igualmente afetados pela barragem (Coutinho \& Morais, 2018). 
$\mathrm{Na}$ Nova Jaguaribara as casas já se assemelham àquelas de conjuntos habitacionais, onde as quadras são bem definidas, planejadas e com pouca mudança entre os modelos (Leite, 2018). Casas homogêneas, não conjugadas, com quadras bem delimitadas e ruas mais amplas. Esses fatores são apontados como viabilizadores de uma maior sensação de distanciamento afetivo e isolamento social, bem como facilitadores de atitudes de indiferença aos espaços urbanos. Todo esse planejamento, também teve a preocupação de manter todos os moradores próximos uns aos outros, ou seja, as pessoas permaneciam o mais próximo possível dos que já eram seus vizinhos na antiga cidade. Alguns pontos simbólicos, como igreja matriz e ainda a igreja do Poço Comprido, antigo distrito do município, foram construídas na nova cidade como réplicas da antiga sede, na tentativa, de amenizar os impactos de tal mudança (IBGE, 2020).

Não obstante o planejamento e estruturação da nova cidade, visando uma melhor infraestrutura básica, os moradores se depararam com desafios de ordem física e emocional, após o deslocamento compulsório. O primeiro desafio encontrado foi o fato de estarem agora estabelecidos a uma distância maior do Rio Jaguaribe, fonte de renda da população, o que alterou as relações de subsistência, antes muito ligadas ao rio e, consequentemente gerou maiores despesas para o sustento (Leite, 2018).

A mudança compulsória foi experimentada com profunda tristeza, resistência e ansiedade pela população, visto que os laços e vivências na antiga cidade seriam abandonadas, dando lugar a incerteza do novo. A Psicologia Ambiental ressalta, que, dada à conexão que o ser humano estabelece com o lugar, e a construção de símbolos e significados presentes nesta relação, esse tipo de rompimento é extremamente danoso e pode deflagrar doenças de natureza psicossomática (Cavalcante \& Elali, 2018; Elali \& Medeiros, 2017; Martins, 2020). O apego ao lugar existente entre os moradores da antiga Jaguaribara manifesta-se, ainda hoje, na dificuldade de apropriação da nova cidade e no surgimento de resistências e conflitos sociais. Essa dificuldade tem como pano de fundo o ressentimento por não terem sido considerados no planejamento decisório e por não usufruírem de todos os benefícios da barragem. A barragem, através do canal da integração, proporciona água apenas para abastecer a capital do Ceará. Este fato tem sido motivo de ultraje e prejuízos, pois aos moradores da Nova Jaguaribara é negado o direito de usufruir dessa água.

De acordo com Morais e Monteiro (2019) o deslocamento programado compulsório de uma população gera impacto e perturbações, pois apesar de sua natureza "planejada", têm consequências traumáticas e muitas vezes revelam-se permeadas por sentimentos e ações de resistências por parte das populações atingidas. Negligenciar os impactos gerados na saúde mental das populações afetadas durante os processos de deslocamentos programados por grandes empreendimentos é, portanto, consentir que o estado e as empresas privadas sejam negligentes com as suas responsabilidades e investimentos em saúde e qualidade de vida dessas populações. Em virtude das grandes e profundas 
modificações sofridas nos processos de realocações, ressalta-se que os impactos e os comprometimentos ocorridos na saúde mental das populações deslocadas ocorrem tanto em nível individual, como coletivo (Guimarães, Alves, Costa \& Dourado, 2018; Martins, 2020).

Em decorrência das perdas ocasionadas pela construção da barragem e consequentemente do deslocamento compulsório dos moradores da cidade de Jaguaribara, pode-se considerar que a mudança foi considerada brusca para população, o que pode ocasionar, segundo Torlai (2010), uma grande ruptura na vida dessas pessoas, podendo deixá-las inesperadamente enlutadas, já que houve perdas tanto de ordem psíquicas como matérias. "O luto é caracterizado como uma perda de um elo significativo entre uma pessoa e seu objeto, portanto, um fenômeno mental natural e constante no processo de desenvolvimento humano" (Cavalcanti, Samczuk \& Bonfim, 2013, p. 88). Assim sendo, leva-se em consideração que o impacto sofrido pelos moradores de Jaguaribara representa questões significativas, uma vez que houve perderas de vivências simbólicas com a cidade antiga.

É importante levar em consideração que existem diversas perdas que podem estar interligadas a um processo de luto, sem obrigatoriamente envolver um processo de morte física, visto que elas rompem um vínculo que é considerado concreto que acabam provocando o luto, tendo como exemplo a perda que foi vivenciada pelos moradores de tudo que foi construído e conquistado durante a permanência naquela cidade. Essa perda pode ser considerada múltipla, única ou total tendo como bases do luto, a resistência à mudança e a relutância em renunciar a algo (Alves, 2014).

Portanto, a Psicologia Ambiental, área interdisciplinar que investiga a relação pessoa-ambiente e os desdobramentos comportamentais, psicológicos e sociais dessa interação, visa discutir através deste artigo as consequências do deslocamento programado compulsório para a população de Nova Jaguaribara. Ademais, possui também como objetivo pensar as consequências para outras populações deslocadas, tendo em vista a inópia de estudos que demonstram os prejuízos que produzem na saúde mental. Considera-se, fundamental identificar o aparecimento e a manutenção de sintomas de adoecimentos, como o luto não elaborado e sinais sofrimento psíquico, possibilitando assim, intervenções que possibilitem uma melhor adequação e enfrentamento destes processos pelas populações afetadas.

\section{MÉTODO}

Realizou-se uma pesquisa exploratória, descritiva e qualitativa, na cidade de Nova Jaguaribara, com 09 participantes, 03 homens e 06 mulheres, com idades entre 30 e 60 anos, que vivenciaram o deslocamento programado compulsório da Velha Jaguaribara para a nova cidade planejada. 
O presente artigo foi submetido ao Comitê de Ética em Pesquisa da Universidade de Fortaleza (UNIFOR), CAAE: 09454919.9.0000.5052. Após a aprovação, foram contatados os participantes e solicitado que esses lessem e assinassem o TCLE Termo de Consentimento Livre e Esclarecido, cujo modelo foi elaborado de acordo com as resoluções $n^{\circ} 466 / 12$ e 510/16. Os objetivos da pesquisa, a garantia do anonimato, e os procedimentos adotados foram detalhados. Neste trabalho, todos os aspectos éticos referentes a pesquisas envolvendo seres humanos foram considerados.

A natureza qualitativa do estudo possibilitou apreensão dos significados e das vivências dos entrevistados. A fase exploratória teve como objetivo a imersão dos pesquisadores no campo de estudo, a fim de favorecer o percurso teórico e metodológico (Pesce \& Abreu, 2019). A pesquisa de campo deu-se em dois momentos, com entrevistas semiestruturadas individuais e a vivência do grupo focal enquanto coletivo, possibilitando assim uma comparação dos resultados obtidos. Primeiramente foram realizadas entrevistas semiestruturadas individuais, com o auxílio de um gravador, com os todos participantes.

Posteriormente, deu-se a condução do grupo focal, como instrumento de pesquisa qualitativa. Entende-se que o grupo focal seria um meio eficaz para aprofundamento do acesso a informações acerca do fenômeno pesquisado. Os conteúdos e temas abordados relacionaram-se às perdas ocasionadas pela mudança, a adaptação à nova cidade, ao luto decorrente da perda do lugar, e ao sofrimento psíquico, resultado do processo de deslocamento programado compulsório (Backes, Colomé, Erdmann \& Lunardi, 2015).

Passada a fase das entrevistas e dos encontros do grupo focal, os dados foram transcritos e compilados, e desse modo, examinados através da análise de conteúdo categorial. A análise dos dados possibilitou a compreensão dos discursos a partir da ocorrência de padrões e de termos utilizados pelos participantes. Os fenômenos equivalentes foram separados e categorizados para uma melhor compreensão e confirmação dos pressupostos.

\section{RESULTADOS E DISCUSSÃO}

A análise dos dados compilados através das duas técnicas de coletas possibilitou a construção de uma compreensão a respeito do fenômeno pesquisado, assim como a confirmação das hipóteses anteriormente levantadas. A despeito dos anos que já se passaram, os depoimentos possibilitaram a exteriorização de forte vinculação com a cidade inundada, a dificuldade de adaptação a nova cidade e a persistência do sofrimento psíquico.

A divisão de categorias possibilitou o surgimento e a percepção dos fenômenos equivalentes e a confirmação das hipóteses anteriormente levantadas. Os aspectos apreendidos foram divididos em três categorias, e descritas abaixo: 1 - 
Relação de apego com a antiga cidade; 2 - Desdobramentos do processo de adaptação; 3 - Luto não elaborado e sofrimento psíquico.

\section{RELAÇÃO de APEGO COM A ANTIGA CIDADE}

A categoria (1) apresenta a relação de apego que os participantes mantêm com a Antiga Jaguaribara e descreve como esta postura, em relação à antiga cidade, é propiciadora e reforçadora de atitudes de resistência e de comparação com a nova cidade. Apego ao lugar pode ser definido como o vínculo emocional que o indivíduo estabelece com o ambiente físico e psicossocial, bem como o grau de proteção e sentido que este ambiente produz para e no indivíduo (Bomfim \& Souza, 2018; Elali \& Medeiros, 2017).

O quanto que essas pessoas sofreram, o quanto que essas pessoas não se encontraram, você ter que abandonar seu fogão de lenha, pra vir pra cá que é uma outra realidade, que nenhuma casa recebeu um fogão de lenha, quer dizer, não houve respeito à cultura do povo de Jaguaribara, não houve um acompanhamento. (Participante 1 - 44 anos).

Entende-se que, para além de uma dimensão física, a cidade é lugar de elaboração de significados e signos, de construção identitária e subjetivação. Compreender a relação que o indivíduo possui com o lugar, corresponde a entender como se dá o processo de apego/vínculo que foi adquirido ao longo da vida (Bomfim, Delabrida \& Ferreira, 2018). Para a psicologia ambiental, essa compreensão é fundamental, pois possibilita o estabelecimento prévio de estratégias que visem à redução de danos e a promoção de saúde (Guimarães et al., 2018).

$\mathrm{Na}$ antiga cidade, o que eu posso relatar dela era o que? Que a vida relacionada com as duas cidades, era bem mais fácil de se viver, até porque, o rio que nós tínhamos que era um rio perene, ele todo dia dava sobrevivência pros que eram mais carentes e hoje aqui na cidade nova, a gente sentiu dificuldades com relação a isso, porque pra você ter essa riqueza que nós tínhamos lá, você tem que se deslocar uns 3,4 km e não oferece a mesma riqueza que nós tínhamos porque lá, o agricultor vivia do que lá o rio oferecia (Participante $2-53$ anos).

Uma das principais peculiaridades na relação de apego é a vinculação afetiva positiva com o lugar, que favorece sensação de bem-estar, segurança e pertencimento. Sendo assim, o inverso disso conceberia a oportunidade e o surgimento de conflitos e adoecimentos individuais e coletivos (Bomfim \& Souza, 2018; Elali \& Medeiros, 2017). 
A Velha Jaguaribara é lembrada e descrita pelos que vivenciaram o deslocamento como o lugar seguro, o conhecido, o lugar de vinculação e pertencimento, enquanto a Nova Jaguaribara é descrita como lugar de não adaptação, surpresa e incerteza. A relação de apego com a antiga cidade, o ressentimento provocado pela perda da autonomia em decisões diretamente relacionadas às suas vidas, agregado ao fato de não terem sido beneficiados com a construção da barragem, são fatores que intensificam dificuldade de vinculação com a nova cidade (Coutinho \& Morais, 2018; Elali \& Medeiros, 2017).

... Foi comprovado aí que eles queriam essa barragem para ser caixa d'agua pra Fortaleza e na época, não só pra isso, mas pra enricar os proprietários também, a maior parte daqui vai pro Pecém, porque é uma aberração muito grande, esse canal daqui pra Fortaleza, um morador que vive vizinho ao canal não poder pegar uma lata d'agua porque é tudo vigiado, vigilante armado (Participante 1 - 44 anos).

...tanto que nós não tivemos nenhuma preparação psicológica, que o povo não se apoderou dessa cidade, não se sente dono, quantas praças não já foram construídas aqui, com brinquedo e casinhas e é destruído? Porque não se sente dono! Isso aqui não foi eu que fiz, eu não construí, não vi nascer, não vi crescer? (Participante 1 - 44 anos)

Compreender que as cidades possuem uma dimensão física, social e afetiva, e que ambas as dimensões não se separam, é fundamental para assimilar o grau de investimento afetivo que o indivíduo confere ao lugar, e para que possam ser planejadas intervenções que possibilitem um melhor delineamento de projetos urbanos (Elali \& Medeiros, 2017; Guimarães et al., 2018). Entende-se que devido à ligação de interdependência que o ser humano possui com o lugar, não há como assimilar o indivíduo deslocado do espaço onde vive, pois, ele só pode ser compreendido integrado ao seu ambiente (Bomfim \& Souza, 2018; Cavalcante \& Elali, 2018; Silva, 2018).

Sendo assim, investigar os aspectos interdependentes, bem como os fatores existentes na relação de apego ao lugar, antes, durante e após os deslocamentos programados, possibilita um melhor desenvolvimento de recursos e projetos para as comunidades afetadas, bem como um processo mais satisfatório de readequação ao novo lugar/ambiente (Guimarães et al., 2018).

\section{DESDOBRAMENTOS DO PROCESSO DE ADAPTAÇÃO}

A categoria (2) refere-se às dificuldades encontradas pelos participantes no processo de apropriação da Nova Jaguaribara, compreendendo que todo processo de mudança, mesmo as consideradas positivas, envolvem fatores tensores e estressores, e a necessidade de adaptação (Leite, 2018). Ademais, 
buscou-se perceber, entre os entrevistados, se fatores como a idade e o tempo de habitação na antiga cidade, de alguma maneira ampliariam a dificuldade de apropriação da nova cidade e o sentimento de desamparo.

Verificou-se que, a vivência do processo de deslocamento programado compulsório provocou em muitos moradores, em especial nos mais velhos, um sentimento de inadequação e de não pertencimento à nova cidade, caracterizado pela fragilidade da vinculação ao novo lugar e ao sentimento de perda de suas identidades. A relação com a Velha Jaguaribara constituiu-se através de gerações, de experiências e de significados. Bomfim, Delabrida e Ferreira (2018) afirmam que o lugar, para além de uma dimensão física, comporta uma dimensão simbólica, que é permeada por afetos, memórias, significados e valores, configurando-se como parte do eu, como parte da identidade coletiva desta população.

No contexto dos deslocamentos populacionais forçados, a relação de apego ao lugar fortalece a manifestação de sentimento favorável em relação ao lugar perdido, logo, evidencia-se demonstrações de perda profunda pós-realocação, obstaculizando o processo de apropriação deste novo lugar (Morais \& Monteiro, 2019). Segundo Martins (2020) os efeitos dos descolamentos compulsórios podem reverberar por muitos anos na vida dos moradores de uma cidade atingida. Com o passar do tempo, A Velha Jaguaribara permanece presente na memória e na saudade dos mais velhos.

... nunca recebi na minha casa a visita de uma assistente social querendo saber qual o impacto da mudança, como que era que tava sendo a adaptação na nova cidade... coisas que talvez tivessem sido fundamentais pra fazer com que as pessoas se sentirem donas dessa cidade (Participante $3-30$ anos).

Estudos da Psicologia Ambiental afirmam que, quanto maior for o tempo que um indivíduo habita em um determinado lugar, maior a probabilidade de ele constituir vínculos e raízes profundas com este ambiente, propiciando uma sensação de "estar em casa". Este processo, denominado de enraizamento, considera que existe uma estreita relação entre tempo de habitação e vinculação com o lugar, todavia, consideram-se fatores como o investimento que o indivíduo faz naquele lugar e os aspectos individuais (Elali \& Medeiros, 2017; Massola \& Svartman, 2018).

... aqui acolá eu vou na cidade velha, eu vou lá, sento lá no local da minha casa, mato um pouco a saudade... (Participante $4-49$ anos).

A sensação de "estar em casa" é nomeada por alguns teóricos como uma característica primordial do enraizamento, e descreve uma disposição do 
indivíduo em centralizar-se ao redor de um lugar definido ao qual ele pertence. Entende-se que devido à ideia literal de pertencimento à antiga cidade e a vivência dolorosa do processo de ruptura, os moradores se depararam com grandes dificuldades de apropriar-se do novo lugar, em especial os mais velhos, por terem vivido o processo em sua totalidade (Leite, 2018; Massola \& Svartman, 2018).

É assim, uma pessoa idosa fica triste, aí, às vezes vem o pior porque a gente escuta falar: "ah ela sente muita saudade da velha cidade" " ah amofinou, não sai mais de casa" e isso tudo tem um porquê, né? Porque você não vai ficar assim triste de repente, com qualquer coisa né? Uma coisa banal... e a Jaguaribara velha é a sua raiz! É a sua história! (Participante 5 65 anos).

O desenraizamento é percebido como uma situação indesejável, em geral agressiva e penosa, pois neste processo o indivíduo é separado de suas origens pessoais, sociais e históricas (Massola \& Svartman, 2018). Evidencia-se, embutido nos discursos de alguns moradores mais antigos, uma não elaboração ou não apropriação desse novo lugar. A despeito do tempo decorrido desde o processo da mudança, os impactos da perda da cidade que os constituía simbolicamente e identitariamente ainda permanecem presentes atualmente (Bertini, 2015). No caso dos moradores de Jaguaribara, observa-se a manutenção da dor pela perda da sua cidade e um luto a ser ainda elaborado. A vivência do processo de desenraizamento ocasionado por deslocamento programado compulsório pode ser equiparada a um processo de luto antecipatório devido à intensidade da ruptura sofrida (Silva, 2018).

Na população mais jovem, o deslocamento não produziu efeitos tão dolorosos, especialmente para os que chegaram bem pequenos na nova cidade ou nasceram lá. Para estes, a Velha Jaguaribara é conhecida e experimentada através dos relatos dos mais velhos, das histórias contadas e ensinadas na escola.

Porque os laços da gente tão tudo lá, essa geração que vai nascer aqui, que tá nascendo aqui, daqui a 20, 15 anos ela já não tem mais o laço que a geração que veio de lá tem (Participante $4-49$ anos).

O luto ainda vive presente... exatamente nessas pessoas mais velhas, que é como eu digo, construíram suas histórias lá, a gente vindo como criança... criança é criança em todo lugar tá bom, então assim, tudo é novo... novidade é sempre bom... Então, assim, e essas pessoas ainda sofrem (Participante 6 - 30 anos). 
Entende-se que mudanças com características duradouras, por sua condição de permanência, solicitam do indivíduo um processo de adaptação mais intenso. Assim sendo, as pessoas tendem a utilizar todos os recursos que dispõem, e todas as estratégias diante da nova situação, com a finalidade de alcançarem êxito, todavia essa mobilização é desencadeadora de estresse, sofrimento e adoecimento (Pozzebon \& Ferreira, 2018; Torlai, 2010).

Teve muita gente que teve resistência em se adaptar aqui, não queriam e até hoje tem gente que não gosta daqui com meu pai, meu pai não gosta daqui, não se acostuma aqui... e como outros e outros... Outras pessoas não se acostumam aqui com a cidade (Participante 7 - 44 anos).

Ademais, a padronização das casas, formando um grande e uniforme conjunto habitacional constitui-se como outro aspecto no planejamento da Nova Jaguaribara, que é desfavorável ao processo de apropriação do lugar. Essa padronização, desprovida de simbologia e com poucas referências à antiga cidade, foi causadora de desorientação espacial, em especial para os mais idosos. Constatou-se que a criação de espaços análogos viabilizou uma sensação de inexistência de sentido em relação ao lugar, proporcionando uma potencialização para o surgimento de adoecimentos (Frota \& Duarte, 2016; Pozzebon \& Ferreira, 2018).

Em seus estudos sobre a problemática do Castanhão, Bertini (2015), relata que muitos moradores construíram banquinhos nas calçadas e realizaram reformas na estrutura de suas casas. Esse movimento pode ser percebido tanto como uma ação de resistência, como uma forma de recriar nessa nova realidade um lugar potencializador de afetos e de memórias. Por conseguinte, Bomfim e Souza (2018) reforçam que no planejamento e construções de espaços/lugares, além da estrutura física, devem ser consideradas as produções afetivas envolvidas na relação pessoa-ambiente. Apesar das réplicas construídas como tentativa de facilitar a adaptação da população a Nova Jaguaribara, identificou-se a dificuldade por parte dos antigos moradores de apropriação deste lugar, e os transtornos decorrentes disso.

\section{LUTO NÃO ELABORADO E SOFRIMENTO PSÍQUICO}

A categoria (3) aborda a complexidade dos processos encontrados na vivência dos entrevistados, e que são comparados ao luto não elaborado, decorrentes de um processo de luto antecipatório, com sintomas e manifestações de sofrimento psíquico. O termo luto antecipatório designa um conjunto de processos que sobrevém ao indivíduo diante da perspectiva ou ameaça progressiva de perda (Santos, Yamamoto \& Custódio, 2018).

Observa-se, portanto, que no contexto dos deslocamentos programados forçados, é comum a identificação de sinais de luto antecipatório na população 
afetada, já que as repercussões psicológicas negativas se iniciam na fase prédeslocamento, e repercutem no percurso do processo e pós-realocação. Em geral percebe-se a manifestação de sinais e sintomas como sentimento de perda intensa e dolorosa, anseio ou ansiedade, inadequação, desamparo, tom depressivo, sintomas psicossomáticos análogos ao estresse e auto exigência em adaptar-se ao novo ambiente, comuns a esse tipo de luto. Entretanto, ressalta-se que as manifestações variam de indivíduo para indivíduo, bem como o tempo de duração e os recursos de enfrentamento que cada um utiliza para lidar com a perda (Santos et al., 2018; Silva, 2018).

Eu sei que o luto não tá só atrelado à morte, mas não deixa dessa mudança ter sido morte, porque tudo! Até os defuntos, foram exumados para ser levados pra cá, então não tem como ver sem ser como morte, foi uma cidade que morreu pra dar vida a outra, mas morreu! (Participante 3 - 30 anos).

Após o deslocamento em massa para a nova cidade, todos os prédios foram demolidos, e posteriormente inundados. As águas agora ocupariam os espaços e os lugares que constituíam parte da identidade deste povo. No entanto, apesar da aniquilação física da Velha Jaguaribara, identifica-se ainda estabelecidos sinais e relatos de uma ligação profunda com o lugar, vivida de forma saudosa e dolorosa. Cientes da ruptura e no esforço de manter viva a ligação com o lugar perdido, a população registra histórias e memórias, através de fotos, vídeos e livros, para que esta não se perca para sempre (Frota \& Duarte, 2016; Silva, 2018; Torlai, 2010).

Diante de enormes conflitos e de uma luta desigual devido à influência e ao controle das forças governamentais e empresariais as populações ainda se veem confrontadas com a complexidade da perda, que envolve fatores sociais, físicos, econômicos e afetivos. Esse tipo de deslocamento programado compulsório deflagra uma série de efeitos negativos nas populações afetadas, sendo desencadeador de adoecimento, pois, maximiza a sensação de perda e vulnerabilidade social, e acarreta na redução da autonomia e da soberania do indivíduo em realizar suas escolhas (Silva, 2018).

A estrutura da nova cidade possui pavimentação e sinalização, bem como saneamento básico, energia e telefonia. Como consequência do processo de modernização, um pequeno aeroporto foi construído no novo local. A Nova Jaguaribara, portanto, em seu modelo e ordenamento, possui uma estrutura física mais adequada e maior que a Velha Jaguaribara, o que permitiu que muitos moradores vivenciassem uma melhoria em suas condições de vida (Leite, 2018). Contudo, apesar dos benefícios proporcionados na estruturação física da Nova Jaguaribara, a vinculação dos moradores com a cidade inundada permanece viva e resistente e mesmo depois de anos da mudança, os impactos provocados na 
saúde mental da população, devido à intensidade da ruptura ocorrida, permanecem e são apontados como um processo de luto não elaborado.

Gerou um luto! Porque nós deixamos nossas raízes, que tivemos que matar pra tentar viver uma nova história aqui, na nova cidade. (Participante $2-53$ anos).

... o sentimento dele é que foi arrancado o rio da cidade dele, ele foi arrancado do rio, ou o rio foi arrancado dele, e ele morreu nesse luto! Fizeram uma piscininha em casa, mas nunca que aquela piscina ia ser o rio que ele gostava de tomar banho. (Participante 1 - 44 anos).

O luto é uma vivência única, tida como necessária, e caracterizada em geral como uma separação significativa e permanente entre a pessoa e o seu objeto perdido. E ainda que esta experiência possa ser explicada de diversos pontos de vista, o luto sempre está atrelado a uma perda expressiva para o indivíduo ou ao término da vida. No luto "normal", o indivíduo consegue tolerar e administrar a perda através de seus recursos, sem maiores prejuízos a sua integridade emocional e psíquica, conseguido, com o passar do tempo, construir novos vínculos e investir afetivamente em novos objetos (Ondere \& Lisboa, 2017).

Entretanto, no luto não elaborado ou complicado, o indivíduo encontra-se imerso em um universo de dor e desespero, progressivo, o que torna mais difícil a elaboração. Na singularidade da vivência, alterna-se intensidade e maneira de viver o luto, porém a dor da perda é algo sempre percebida. Neste tipo de luto o indivíduo não consegue reagir de maneira efetiva, sente dificuldade em construir novos vínculos e em investir na vida. Ademais, um processo de luto não elaborado pode irromper em reações disfuncionais, como raiva e agressividade, além de expor o indivíduo a um intenso sofrimento psíquico e possíveis doenças psicossomáticas (Ondere \& Lisboa, 2017; Santos et al., 2018).

É, eu me lembro muito de lá, toda vida que eu falo da Jaguaribara velha eu choro (se emociona) toda vida! (Participante $8-55$ anos).

...eu costumo muito dizer, que nós passamos por um trauma muito grande social, incorrigível, não há nada que hoje o governo possa fazer, para suprir essa carência, porque olhar as fotos, conhecer a história, saber que a gente viveu tanta coisa bonita, saber que tudo isso podia ter sido evitado, é um preço muito alto e o governo, nem querendo, nem querendo que ele não quer e nem se propôs a pagar o preço ainda... (Participante 1 - 44 anos). 
É importante salientar que a vivência do luto é um processo singular, intransferível e de difícil mensuração, sendo assim, presume-se que somente o próprio indivíduo, na vivência do processo, é que consegue determinar e/ou qualificar com uma maior precisão a medida do seu sofrimento e o tempo necessário para sua elaboração. A despeito de ser experienciado individualmente e de possuir características peculiares a cada indivíduo, a vivência do luto pode ocorrer coletivamente, como percebido no caso das populações que atravessam um percurso de deslocamento programado forçado (Ondere \& Lisboa, 2017).

Martins (2020), ressalta a importância de se considerar a dimensão social e afetiva nos processos de descolamentos compulsórios, devido às inúmeras perdas imateriais, a fragilização dos vínculos sociais e os graves danos psíquicos decorrentes. Como consequência, evidencia-se a necessidade de uma maior avaliação dos impactos produzidos por deslocamentos programados forçados em decorrência de grandes empreendimentos, considerando, assim, manifestações de luto não elaborado e sinais de sofrimento psíquico e os efeitos proporcionados pela negligência do cuidado às populações afetadas. A presença da psicologia ambiental nesta avaliação é fundamental, uma vez que ações públicas de grande magnitude podem propiciar o surgimento de transtornos mentais e comportamentais que impactam de forma prolongada a vida e a saúde das populações deslocadas.

\section{CONCLUSÃO}

A água é um bem vital, e a sua continência em decorrência da escassez e irregularidade do período chuvoso, impulsionam projetos de construção de barragens por entidades governamentais e empresas privadas. Em geral, como consequência desses grandes empreendimentos, vê-se a necessidade do deslocamento programado compulsório de populações inteiras para outras áreas. Em deslocamentos dessa natureza, evidencia-se que as populações afetadas são expostas a situações extremamente danosas, com sensação de perda e desorientação espacial, aumento nos níveis de estresse, bem como a manifestação de sofrimento psíquico. Em alguns casos percebe-se a manutenção dos sinais de transtornos psíquico e doenças resultantes da transição.

Embora, tenham-se construído réplicas de pontos significativos da antiga cidade, na tentativa de facilitar a adaptação ao novo ambiente, nota-se que a reprodução de espaços homogêneos torna mais complexa a identificação de singularidades culturais e simbólicas. Este fator dificulta a relação de apego ao novo lugar e favorece a sensação de indiferença aos espaços coletivos. Outra particularidade percebida e apontada como viabilizadora de aspectos negativos na relação homem-ambiente, foi a abrupta mudança no formato das novas casas, não conjugadas, homogêneas e similares a um conjunto habitacional. Este aspecto é apontado como algo que pode ter possibilitado o distanciamento afetivo e social, viabilizando maiores traços de isolamento. 
O ordenamento uniforme das ruas na nova cidade propiciou a manifestação de sinais de desorientação espacial, em especial nos mais idosos. Aspectos de homogeneidade em espaços urbanos potencializam a sensação de não pertencimento e de indiferença ao lugar. Portanto, em relação a projetos urbanos, verifica-se a importância de compreender o sentido do lugar para o indivíduo e para a comunidade, visto que o espaço físico comporta uma dimensão afetiva, social e identitária e é responsável por profundas afetações.

Em graus variados, percebe-se nos relatos dos participantes, a dificuldade de apropriação da nova cidade e a preservação de um vínculo profundo com o lugar perdido. Fatores que dificultaram a vinculação e apropriação do novo lugar são o ressentimento por não terem sido considerados no planejamento decisório e por não usufruírem dos benefícios da barragem. Essa dificuldade foi e é vivenciada de maneira mais potente pelos mais velhos, ratificando o conceito de enraizamento na Psicologia Ambiental, no qual afirma que, enraizar-se implica em vincular-se ao lugar. Contudo, faz-se necessário ressaltar, que existem particularidades nesse processo, dependendo do tempo de habitação e do nível de investimento do indivíduo para com o lugar.

A perda do lugar pode ser classificada como um processo de luto antecipatório, onde se percebem traços de ansiedade, estresse, depressão, perda da autonomia, dentre outros aspectos de intenso sofrimento psíquico. O luto é um processo necessário diante da perda, pode ser experimentado de maneira individual, ou coletiva, porém, quando negligenciado, pode incidir em um luto não elaborado, com sinais e sintomas de adoecimento. Entende-se que esta vivência respeita aspectos singulares de cada indivíduo.

É possível que a Velha Jaguaribara, registrada na memória e no discurso dos antigos moradores, se hoje existisse já não seria a mesma, pois transformações em algum nível estariam presentes, decorrentes de fatores como o avanço da tecnologia ou mesmo da globalização. Entretanto, reconhece-se que os processos de deslocamentos programados compulsórios, decorrentes de grandes empreendimentos, envolvem questões extremamente complexas e que as populações afetadas apresentam similaridades nos padrões de sofrimento e de adoecimento.

As correlações de sofrimento psíquico e adoecimento, encontrado nas populações afetadas, corroboram com sinais de uma profunda ruptura e servem como pressuposto para refutar argumentos de que estes projetos só proporcionariam melhoria na qualidade de vida das populações. Devido à gravidade das implicações, a psicologia ambiental ressalta a necessidade e a urgência de um maior aprofundamento neste tema.

Desenvolver e aprimorar pesquisas sobre os impactos humano-ambientais, decorrentes de processos de deslocamentos programados compulsórios, bem como investigar suas repercussões a curto, médio e longo prazo é primordial. Esse tipo de análise é uma estratégia que possui extrema relevância na 
elaboração de novos projetos e na busca de recursos que promovam saúde e qualidade de vida para as populações atingidas, posto que entidades governamentais e empresas privadas são responsáveis pelos danos causados, que certamente se revelam mais impactantes quando realizados sem a devida atenção aos processos psicológicos associados aos lugares de vida das pessoas.

Estratégias que possibilitem a redução de impactos e danos, e que venham a potencializar aspectos de autonomia, adaptação e promoção saúde para estas populações, são fundamentais para o planejamento de futuros empreendimento desta natureza. Conclui-se, portanto, a importância de se estudar estes aspectos, visto que o luto relacionando a mudanças de cidades decorrentes de inundações programadas é algo novo dentro do campo de pesquisa.

\section{REFERÊNCIAS}

Alves, G. (2014). Desastres: Intervenções em Luto coletivo. Santos, F., Schilemann, A. \& Solano J. (orgs.). Tratado Brasileiro sobre Perda e Luto (pp. 415-423). São Paulo, SP: Atheneu.

Backes, D., Colomé, J., Erdmann, R., \& Lunardi, V. (2011). Grupo focal como técnica de coleta e análise de dados em pesquisas qualitativas. O mundo da saúde, 35(4), 438-442. Recuperado de http://www.saocamilo-sp.br/pdf/mundo saude/88/10 GrupoFocal.pdf.

Bertini, F. (2015). Mudanças urbanas e afetos: Estudo de uma cidade planejada. (Tese de Doutorado) Programa de Pós-graduação em Psicologia Social, Faculdade de Letras da Universidade de Lisboa, Pontifícia Universidade Católica de São Paulo, São Paulo. Recuperado de https://repositorio.ul.pt/handle/10451/18329

Bomfim, Z., Delabrida, Z., \& Ferreira, K. (2018). Emoções e Afetividade ambiental. In Cavalcante, S. \& Elali, G. A. (orgs.). Psicologia Ambiental: Conceitos para a leitura da relação pessoa-ambiente (pp.60-70). Petrópolis: Vozes.

Bomfim, Z., \& Souza, L. (2018). Cidades, espaços e produção de saúde. O Público e o Privado, 16(31), 83-105. Recuperado

de https://revistas.uece.br/index.php/opublicoeoprivado/article/view/2299

Cavalcanti, A., Samczuk, M., \& Bonfim, T. (2013). O conceito psicanalítico do luto: uma perspectiva a partir de Freud e Klein. Psicólogo informação, 17(17), 87-105. https://doi.org/10.15603/2176-0969/pi.v17n17p87-105

Cavalcante, S., \& Elali, G. A. (2018). Psicologia ambiental: Conceitos para a leitura da relação pessoaambiente. Petrópolis: Vozes.

Coutinho, E., \& Morais, M. (2018). Da Construção das barragens aos atingidos: o caso do Açude do Castanhão no Semiárido Cearense (BR). Conferência Internacional de Ambiente em Países de Língua Portuguesa \& XX Encontro REALP \& XI CNA. 8-10 de maio, Aveiro, Portugal, I, 719-728. Recuperado de http://hdl.handle.net/10174/24963

Elali, G., \& Medeiros, S. (2017). Apego ao lugar. In: Cavalcante, S. Elali GA. (orgs.). Psicologia Ambiental: conceitos para a leitura da relação pessoa-ambiente (pp. 53-62). Petrópolis: Vozes.

Frota, M., Jr., \& Duarte R., Jr. (2016) A velha e a nova Jaguaribara (CE): memórias submersas e novas memórias. (Dissertação de mestrado) Programa de Pós-graduação em Arquitetura e Urbanismo e Design do Centro de Tecnologia da Universidade Federal do Ceará, Fortaleza, Ceará. Recuperado de http://www.repositorio.ufc.br/handle/riufc/48806

Guimarães, E., Alves, F., Costa, M., \& Silva, F. (2018). A importância da psicologia no planejamento ambiental: um olhar sobre as situações de desastres naturais. In Anais do 70 Simpósio de Gestão Ambiental e Biodiversidade. (138-141). Três Rios, Rio de Janeiro: UFRRJ. Recuperado de https://www.itr.ufrrj.br/sigabi/wpcontent/uploads/7_sigabi/37GUIMARAES_ESTHER_138a141.pdf 
Instituto Brasileiro de Geografia e Estatística [IBGE]. (2020). Cidades. Recuperado de https://cidades.ibge.gov.br/brasil/ce/jaguaribara/historico

Leite, L. (2018). O novo ordenamento socioespacial em jaguaribara e a percepção do lugar (Dissertação de Mestrado) Programa de Pós-graduação em Geografia do Centro de Ciências e Tecnologia da Universidade Estadual do Ceará, Fortaleza, Ceará. Recuperado de http://www.uece.br/mag/dmdocuments/lilian des\%C3\%A1 leite.pdf

Massola, G., \& Svartman, B. (2018). Enraizamento, tempo e participação na Psicologia Ambiental. Estudos de Psicologia (Natal), 23(3), 293-305. https://dx.doi.org/10.22491/16784669.20180028

Martins, C. (2020). Afetividade em Contextos de Desapropriação: Impactos Psicossociais das Obras do Cinturão das Águas do Ceará em comunidades rurais do município do Crato-CE. (Dissertação de Mestrado) Programa de Pós-Graduação em Psicologia da Universidade Federal do Ceará, Fortaleza, Ceará. Recuperado de http://repositorio.ufc.br/handle/riufc/53589

Morais, T., \& Monteiro, C. (2019). Deslocamentos compulsórios e construção da subjetividade: análise a partir de projetos de desenvolvimento. Revista de Psicologia (Fortaleza), 10(2), 51 57. Recuperado de http://www.repositorio.ufc.br/handle/riufc/46711

Ondere, J., \& Lisboa, C. (2017). Doenças associadas ao luto antecipatório: uma revisão da literatura. Psicologia, Saúde \& Doenças, 18(2), 308-321. https://dx.doi.org/10.15309/17psd180203

Pesce, L., \& de Abreu, C. (2019). Pesquisa qualitativa: considerações sobre as bases filosóficas e os princípios norteadores. Revista da FAEEBA-Educação e Contemporaneidade, 22(40), 19-29. http://dx.doi.org/10.21879/faeeba2358- 0194.2013.v22.n40.p19-29

Pozzebon, F., \& Ferreira, V. (2018). Sintomas depressivos de ansiedade e de estresse em habitantes de munícipio realocado por barragem. Psico, 49(2), 187-195. https://doi.org/10.15448/1980-8623.2018.2.26984

Santos, R., Yamamoto, Y., \& Custódio, L. (2017). Aspectos Teóricos sobre o processo de luto e a vivência do luto antecipatório. Psicologia. pt: o portal dos psicólogos. Recuperado de https://www.psicologia.pt/artigos/textos/A1161.pdf

Silva, J. (2018). Impactos individuais e contextuais do deslocamento forçado na comunidade (Tese de Doutorado) Programa de Pós-graduação em Psicologia Clínica e Cultura, Universidade de Brasília, Brasília, Distrito Federal. Recuperado de https://repositorio.unb.br/handle/10482/35093

Torlai, V. (2010). A vivência do luto em situações de desastres naturais (Dissertação de Mestrado) Programa de Pós-graduação em Psicologia Clínica, Pontifícia Universidade Católica de São Paulo, São Paulo, São Paulo. Recuperado de https://sapientia.pucsp.br/bitstream/handle/14965/1/Viviane\%20Cristina\%20Torlai.pdf

\section{CONFLITOS DE INTERESSES}

Não há conflitos de interesses.

\section{SOBRE OS AUTORES}

Maria Lívia Pinheiro de Freitas é Psicóloga graduada pela Universidade de Fortaleza- UNIFOR e Pósgraduanda em psicologia da Infância. Foi bolsista de Iniciação Científica durante os anos de 2019 e 2020. Atuou como estagiária no Centro de Apoio ao Sujeito no Luto-CASULU entre os anos de 2018 a 2020 Pesquias sobre: Psicologia e Saúde, Psicologia Ambiental e Saúde, luto e Tanatologia. Membra do Centro de Apoio ao Sujeito no Luto- CASULU.

E-mail: livia.p.freitas@outlook.com

(D) https://orcid.org/0000-0003-0939-9954

Renata Bezerra de Holanda Bessa é Mestranda em Psicologia pela Universidade de Fortaleza (UNIFOR), e Graduada em Psicologia na mesma Universidade. Atuou no Programa de Iniciação à Docência da Universidade de Fortaleza em 2018. Pesquisadora voluntária do Laboratório de Estudo das Relações Humano-Ambientais (LERHA) - UNIFOR. Atualmente coordena o grupo de estudos 
Psicologia Ambiental e Saúde do Idoso. Desenvolve pesquisas com ênfase nas áreas: Psicologia Ambiental, Psicologia da Saúde, Saúde do Idoso, Cuidados Paliativos e Tanatologia.

E-mail: renataholandab@gmail.com

(D) https://orcid.org/0000-0003-0402-327X

Karla Patrícia Martins Ferreira é graduada em Psicologia pela Universidade Federal do Ceará (2003) Mestre em Psicologia pela Universidade Federal do Ceará (2006), Doutora em Educação pela Universidade Federal do Ceará, com Doutorado Sanduíche na Université de Nantes - França (2011) e Pós-doutorado em Psicologia pela Universidade de Fortaleza. É atualmente professora do Programa de Pós-Graduação em Psicologia da Universidade de Fortaleza, onde coordena o Laboratório de Estudo das Relações Humano-Ambientais (LERHA). Tem experiência nas áreas de Psicologia, Educação e Saúde, com ênfase em Psicologia Ambiental, Psicologia Social, Psicologia da Educação, Educação Ambiental e Educação Popular e Psicologia Fenomenológico-Existencial.

E-mail: karlafeirrapsi@gmail.com

(D) https://orcid.org/0000-0001-9374-4890

Hélida Arrais Costa Vieira possui graduação em Psicologia pela Universidade Federal do Ceará (2007), mestrado em Ciências do Comportamento pela Universidade de Brasília (2011) e doutorado em Ciências do Comportamento pela Universidade de Brasília (2015), com ênfase em Cognição e Neurociências. É especialista em Neuropsicologia (2009), com registro reconhecido no Conselho Federal de Psicologia. Atualmente é professora da Universidade de Fortaleza e coordenadora do Laboratório de Neuropsicologia do Desenvolvimento - LEPNEURO. Tem experiência na área de Psicologia, com ênfase em Expressões Faciais, Neurociências e Emoção, Avaliação Psicológica e Neuropsicologia.

E-mail: helidacostavieria@unifor.br

(D) https://orcid.org/0000-0002-8325-1520

Ada Raquel Teixeira Mourão possui Doutorado em Psicologia Ambiental pela Universidade de Barcelona (2014), Mestrado em Psicologia pela Universidade de Fortaleza (2003) e Graduação em Administração pela Universidade Federal do Ceará (1989). Atualmente é professora da Universidade Federal do Piauí - UFPI e pesquisadora do Laboratório de Estudos das Relações Pessoa-Ambiente do Programa de Pós Graduação em Psicologia da Universidade de Fortaleza (LERHA-UNIFOR). Atua como investigadora na área de Psicologia Ambiental e estudos urbanos, principalmente em temas relacionados a Espaço Público, Desenvolvimento Urbano e Social, Subjetividade, Identidade de Lugar, conflitos urbanos e cidade como espaço educativo.

E-mail: adamourao@ufpi.edu.br

(D) https://orcid.org/0000-0001-6022-7045 